\title{
Correction to: Assessment of Capacity to Meet Lancet Commission on Global Surgery Indicators in the Federal Capital Territory, Abuja, Nigeria
}

\author{
Jamie E. Anderson ${ }^{1,2,3}$ - Aliyu Baba Ndajiwo ${ }^{1}$ Susuti Aaron Nuhu ${ }^{1,4}$ • \\ Olubunmi Aiyedun Lawal ${ }^{1,5} \cdot$ Joseph O. Amedu ${ }^{1,4} \cdot$ Emmanuel A. Ameh $^{1,6}$
}

Published online: 11 December 2018

(C) Société Internationale de Chirurgie 2018

\section{Correction to: \\ World J Surg \\ https://doi.org/10.1007/s00268-018-4835-z}

In the original article there is an error in Fig. 2. Following is the corrected figure.

The original article can be found online at https://doi.org/10.1007/ s00268-018-4835-z.

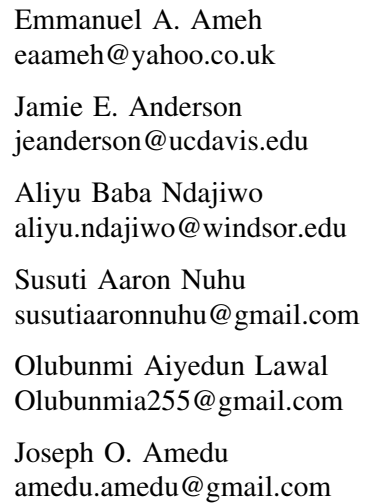

Nigeria National Surgical, Obstetric, Anesthesia, Nursing Plan Committee, Abuja, Nigeria

2 Harvard Medical School Program for Global Surgery and Social Change, Boston, MA, USA

3 Department of Surgery, University of California, Davis, Sacramento, CA, USA

4 Department of Hospital Services, Federal Ministry of Health, Abuja, Nigeria

5 National Association of Nigerian Paediatric Nurses, Abuja, Nigeria

6 Division of Paediatric Surgery, Department of Surgery, National Hospital, Abuja, Nigeria 
Fig. 2 Map of the Federal Capital Territory, Abuja, showing the 6 Area Councils, their populations, and the locations of the district and general hospitals (included in the study), and tertiary referral centers [18]

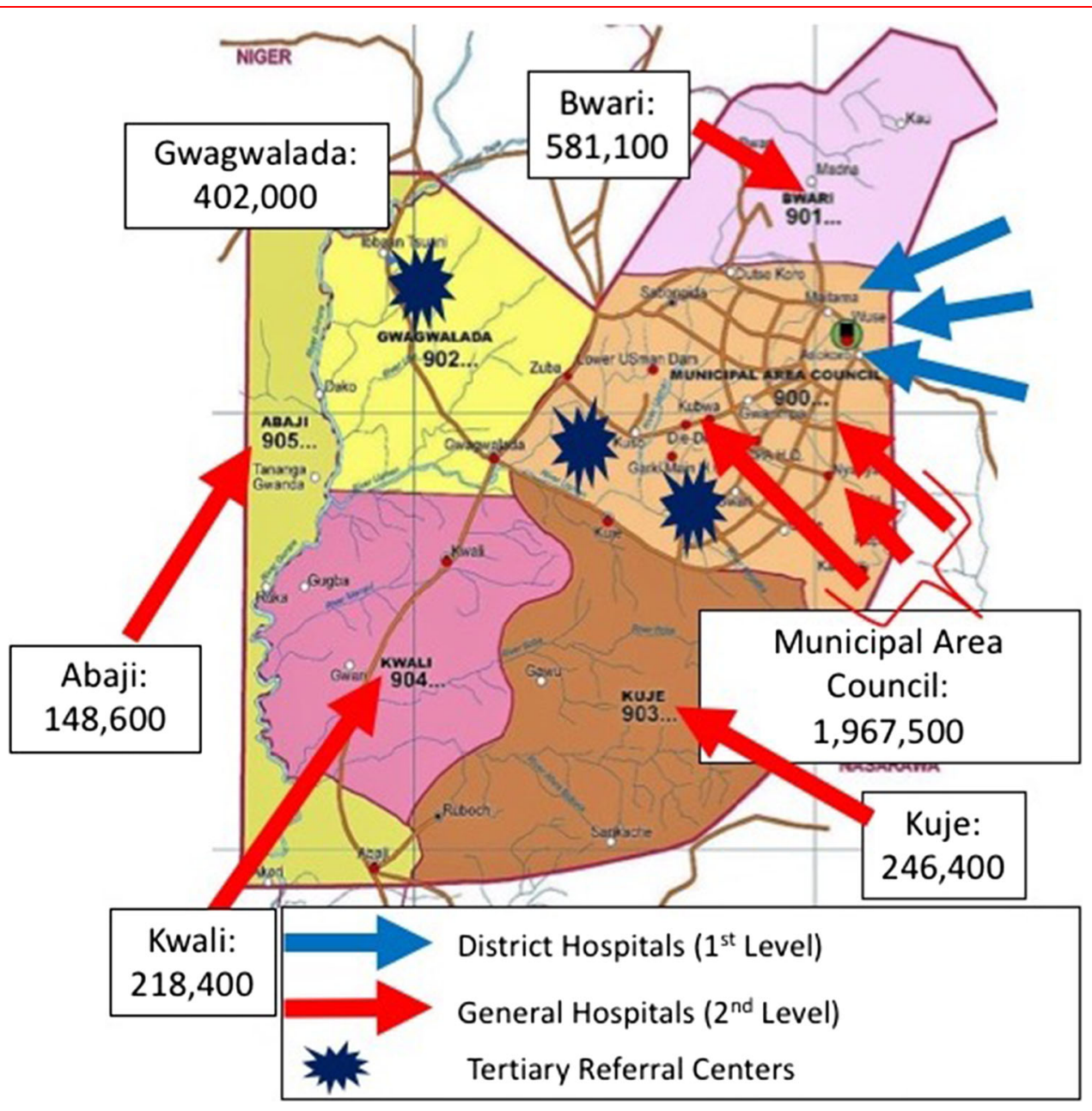

